\title{
GESTÃO DA INDISCIPLINA NA DINÂMICA E ORGANIZAÇÃO ESCOLAR: ESTUDO DE ALGUNS DOS SEUS DETERMINANTES
}

\author{
Fernando Videira dos Santos ${ }^{1}$ \\ Carlos Albuquerque ${ }^{2}$
}

\begin{abstract}
Resumo:
Enquadramento: A indisciplina escolar, como problemática emergente, que nos últimos anos tem vindo a ganhar relevo na comunidade educativa, tem desencadeado um conjunto de reações $e$ múltiplas preocupações nos mais variados quadrantes da Sociedade Portuguesa. Neste contexto, o presente estudo teve como objetivo geral explorar as relações existentes entre determinantes de contexto sociodemográfico, familiar e religioso e a indisciplina escolar percepcionada pelos alunos.

Material e Método: Recorrendo a um estudo de natureza quantitativa, do tipo transversal com características descritivocorrelacionais, inquirimos 772 alunos adolescentes portugueses, na sua maioria do género feminino (52,1\%), com idades compreendidas entre os 12 e os 17 anos ( $M=13,33 ; D p=1.042)$, residentes em meio rural (51,2\%), pertencentes à classe socioeconómica III - Classe Média $(48,4 \%)$ e que frequentam o terceiro ciclo do ensino básico público. $O$ protocolo de pesquisa incluiu instrumentos de medida aferidos e validados para a população portuguesa e a Escala de Indisciplina Escolar Percepcionada por Alunos (EIEPA), cujas propriedades psicométricas certificam a sua qualidade (Alfa de Cronbach = 0,960; Alfa de Cronbach teste re-teste $=0,911)$.

Resultados: As variáveis sociodemográficas (idade, sexo e local de residência) revelaram um efeito estatisticamente significativo sobre a Indisciplina Escolar Percepcionada pelos Alunos. Também se constatou a existência de associações estatisticamente significativas entre as variáveis de contexto religioso (grau de crença na religião e grau de praticante) e todos os factores da escala EIEPA. No que respeita ao estudo do efeito da existência de conversas com o encarregado de educação sobre a forma como o estudante de
\end{abstract}

${ }^{1}$ CEIS20: Centro de Estudos Interdisciplinares do Século XX da Universidade de Coimbra.investvideira@gmail.com

2 Escola Superior de Saúde do Instituto Politécnico de Viseu. cmalbuquerque@gmail.com 
comporta na escola, o mesmo permitiu inferir que este efeito assume significância estatística sobre todos os factores da Indisciplina Escolar Percecionada por Alunos.

Conclusão: As inferências resultantes desta investigação convidam-nos à reflexão sobre a importância da criação $e$ monitorização de programas de ação no domínio da prevenção ou de contingência para uma efetiva redução dos comportamentos indisciplinados perpetrados por Alunos no seio da Escola. Fica claro que esta tarefa, sendo urgente, tem de ser articulada entre toda a comunidade educativa, com envolvimento direto dos pais/encarregados de educação, bem como de outros protagonistas no sentido de se desenvolverem estratégias de intervenção dirigidas às reais necessidades dos adolescentes.

Palavras-chave: Gestão, adolescentes, indisciplina escolar, clima organizacional, escola, família.

\begin{abstract}
:
Framework: School indiscipline, as an emerging issue which has gained importance in educational community in recent years, has generated multiple reactions and concerns in the Portuguese Society. In this context, the present study aims to explore the relationships between determinants of sociodemographic, social-family and religious contexts and school indiscipline perceived by students.

Material and Method: Using a quantitative cross-sectional study with descriptive-correlational characteristics, we surveyed 772 Portuguese adolescent students, mostly female (52.1\%), aged between 12 and 17 years $(M=13,33 ; D p=1,042)$, living in rural areas (51.2\%), belonging to socioeconomic class III - Middle Class (48.4\%) and attending the third cycle of public basic education. The research protocol included measured and validated measurement instruments for the Portuguese population and the Student Perceptual School Indiscipline Scale (EIEPA), whose psychometric properties certify its quality (Cronbach's alpha $=0.960 ;$ Cronbach's alpha re-test $=$ 0.911).

Results: The sociodemographic variables (age, sex and place of residence) revealed a statistically significant effect on school indiscipline perceived by the students. Statistically significant associations were also found between the variables of religious context (degree of belief in religion and degree of religious practices) and all factors of the EIEPA scale. With regard to the study of the effect of the conversations with the caretaker on the way the student behaves in school, this allowed to infer that this effect assumes statistical significance on all the factors of school indiscipline perceived by the students.

Conclusion: The inferences resulting from this investigation invite us to reflect on the importance of creating and monitoring programs of action in the field of prevention or contingency for an
\end{abstract}


effective reduction of undisciplined behaviors perpetrated by students within the School. It is clear that this task, as a matter of urgency, has to be articulated inside the entire educational community, with the direct involvement of parents / guardians, as well as other protagonists in the development of intervention strategies aimed at the real needs of adolescents.

Keywords: Management, adolescents, school indiscipline, organizational climate, school, family.

\section{INTRODUÇÃO}

A indisciplina escolar pode ser considerada como uma das facetas com maior impacto na vida da escola e, por inerência, no processo de ensinoaprendizagem do estudante, tornando-se assim importante conhecer quais os determinantes que estão na base desta mesma indisciplina escolar. De facto, todos os atores educativos reconhecem que, para se agir de forma intencional e consciente, torna-se necessário um conhecimento mais desenvolvido e investigado deste fenómeno, nomeadamente, aferindo conceitos, identificando agentes e fatores implicados, diferenciando atitudes, bem como tentando compreender um conjunto de relações e de inter-relações com outras variáveis que coabitam e estão presentes no seio da escola ou fora dela, uma vez que a escola é reflexo do ambiente que a rodeia.

No entanto, para que se possa compreender este fenómeno, que é a indisciplina escolar, é necessário delimitar o seu significado e evolução no tempo. Poder-se-á afirmar que a problemática da indisciplina escolar tem vindo a ganhar relevo na comunidade escolar portuguesa de forma mais enfática a partir dos anos 90 do século passado. Esta questão tem vindo, daí em diante, a ter uma visibilidade pública muito mais acentuada e por isso a desencadear muitas reações e preocupações nos mais variados quadrantes da Sociedade Portuguesa, sobretudo pela importância que a escola tem e certamente continuará a ter na preparação das novas gerações.

A crescente preocupação da opinião pública com as questões não apenas da indisciplina escolar, mas associadamente da violência escolar, têm desencadeado reacções, constrangimentos e discussões em diversos quadrantes sociais e mesmo políticos. Perante a esta evidência, a verdade é que o Ministério da Educação e Ciência e até as escolas tentam responder a esta discussão, que é deveras pertinente e muitas vezes preocupante, com medidas legislativas, administrativas e pedagógicas, tais como, com a 
publicação e com alguns ajustamentos na legislação, republicação de versões reformuladas do Estatuto do Aluno com medidas mais musculadas, tentando assim tornar os processos de controlo mais ágeis, porventura mais desburocratizados, e que, não há muito tempo, culminou com a publicação de um novo Estatuto do Aluno e Ética Escolar no início de 2012, tendo já sido anunciado pelo poder executivo uma nova revisão deste diploma legal. As escolas, por sua vez, geram um conjunto de regulamentos, restringem o acesso aos estabelecimentos de ensino condicionando-o com recurso a um controlo das pessoas por meio do uso de cartões electrónicos. Em muitos casos recorre-se ao reforço das vedações/gradeamentos e fortalecimento da vigilância nas portarias. Ultimamente recorreu-se ainda, com este propósito, ou pelo menos é esta a justificação que é dada pelas autoridades escolares, à colocação de equipamentos de segurança com a instalação de alarmes, reforçado do policiamento por forças de segurança e à instalação de sistemas de videovigilância com alguma sofisticação técnica.

Convém referir ainda que, nomeadamente, nos últimos quatro anos, Portugal e os Portugueses vivenciaram uma crise financeira cuja amplitude é difícil de descortinar e consequentemente com implicações a vários níveis, quiçá também no domínio da dinâmica e funcionalidade escolar. Vivemos, assim, numa Nação em incerteza mais ou menos latente, num país em que a esperança, por vezes parece estar entorpecida, associada a uma crescente incerteza da Europa, espaço económico e social em que estamos e nos queremos ver inseridos, fundado em princípios humanistas, mas também num espaço cada vez menos comum, muito conturbado com uma globalidade do mundo ocidental, marcado pelo medo de um terrorismo violento que mata sem piedade.

Assim, Portugal e os Portugueses vivem cada vez mais integrados nessa complexa teia global; tudo isto, em coligação com esta incerteza globalizada que nos tolhe e nos atemoriza. O certo é que as preocupações sociais são gigantescas e as perguntas que se levantam sobre esta temática são muitas, justificando, por si só, a abordagem insistente destes contextos. Partindo deste enquadramento, será então oportuno citar Freire (2006, p. 160), que considera que "ao longo dos tempos, houve sempre por parte da escola a preocupação com a transmissão de valores de não-violência às novas gerações, de forma mais ou menos consciente”. O autor acrescenta ainda que "no mundo de hoje, faz cada vez mais sentido que na escola se cultive, de forma intencional, uma educação para a paz, que pressupõe a existência de uma cultura dos valores relativos aos Direitos Humanos”. 
Na escola de hoje esta preocupação está presente, é certo, mas a par desta preocupação deve estar inscrita no que é designado como "código genético" de cada unidade orgânica escolar uma cultura de relação, de cidadania, isto é, para a relação com o(s) outro(s). Por conseguinte, para se agir de forma intencional e consciente, torna-se necessário um conhecimento mais desenvolvido e investigado deste fenómeno ( $a$ indisciplina escolar), nomeadamente, aferindo conceitos, identificando agentes e fatores implicados, diferenciar atitudes, bem como compreender um conjunto de relações e de inter-relações com outras variáveis que coabitam no seio da organização escolar. Nesta linha de pensamento, poderemos considerar a indisciplina escolar um dos fatores que estão presentes e que estão subjacentes nas relações sociais que se desenvolvem no seio da escola. No entanto, parece-nos muito importante que a análise deste domínio temático seja feita de uma forma abrangente, articulada e multifacetada.

Se é óbvio que a indisciplina escolar está intimamente ligada ao sistema educativo, não será menos verdade, afirmar mesmo que há uma cumplicidade muito forte com a sociedade que sustenta esse mesmo sistema educativo, isto é, o meio em que está inserida a escola. Assim, as interações que se verificam no seu seio, os valores em que assenta e os padrões de comportamento socialmente aceites que facilitem a nobre e árdua missão de ensinar/educar detêm na organização escolar um papel determinante.

O termo indisciplina indica-nos a negação de disciplina. Assim, talvez não seja muito prudente separar estes dois termos, disciplina e indisciplina. Recorrendo a uma simples consulta num dicionário de Língua Portuguesa, facilmente concluímos que indisciplina significa: falta de disciplina; desobediência; sublevação; rebelião; desordem... .

Da revisão da literatura que realizámos sobre este tema, podemos salientar que alguns autores consideram que se trata de um conceito ambíguo e até, por vezes, algo contraditório, dado que ele pode ter significados muito díspares, passíveis de traduzir resultados e interpretações também distintas, na medida em que os mesmos nem sempre são concebidos a partir de um mesmo padrão teórico. Assim, e como já referimos, se por um lado não devemos considerar este conceito isoladamente, também não devemos investigá-lo de forma descontextualizada, quer no espaço, quer no tempo e, principalmente, fora do contexto social em que o mesmo ocorre ou ocorreu. 
Com efeito, do que afirma Alonso (2007, p. 291), poderemos deduzir que "embora o termo indisciplina seja um conceito originalmente pedagógico, este foi apropriado por outros campos como o militar e o religioso". Por conseguinte, podemos falar de indisciplina em vários âmbitos sociais: indisciplina escolar, indisciplina familiar, indisciplina partidária, indisciplina sindical (Estrela, 2004).

Consequentemente, como afirma Chiavenato (1993, p. 1), “a vida das pessoas depende das organizações e estas dependem do trabalho daquelas. As pessoas nascem, crescem, aprendem, vivem, trabalham, divertem-se, são tratadas e morrem dentro de organizações”, pelo que somos levados a dizer que a indisciplina aparece relacionada com a sociedade organizacional em que vivemos, em particular com as suas organizações, sejam elas de que tipo forem. Do mesmo modo, estando subjacentes a essa indisciplina organizacional as singularidades que cada uma dessas organizações encerram em si mesmas, podemos considerar que existe um denominador comum associado a essa indisciplina organizacional, que passa por questões como a ética, o social, e consequentemente, pela contextualização do cenário em que ocorre, estando este, sem dúvida, ligado a uma dissonância social mais abrangente.

Por conseguinte, embora possa haver quem ponha em causa a existência de uma verdadeira indisciplina escolar, o certo é que este conceito tem vindo a ser estudado nas suas mais variadas vertentes, dado que parece constituir cada vez mais uma real preocupação tanto para professores como para pais e encarregados de educação e mesmo para os próprios alunos, para políticos, em suma, para a sociedade em geral. São vários os estudos que têm demonstrado que a indisciplina na escola é uma das grandes preocupações dos professores e, em particular, dos que estão no início de carreira.

No que diz respeito às normas de convivência social que decorrem da indispensabilidade da definição de um quadro de expetativas que torne os comportamentos individuais e coletivos mais ou menos padronizados, estes comportamentos a que nos referimos não são nem mais nem menos do que aqueles que o senso comum define como os da cidadania, do saber estar com os outros, do respeito mútuo e da capacidade de autocontrolo que permita não colocar em causa a liberdade dos outros.

Como confirmam Amado e Freire (2005), estes aspetos asseguram aos conceitos - disciplina/indisciplina - um caráter polissémico, fazendo depender o seu sentido dos contextos sociais e do quadro de valores que regula os mais diversos níveis a vida quotidiana. Em suma, poder-se-á 
dizer que estamos perante não só de conceitos com uma grande amplitude, mas também de fenómenos de uma grande complexidade, que tantas e tantas vezes são tratados de forma imprecisa, mormente pelos média insaciáveis de sensacionalismos que, na maior parte das vezes, dão uma visão distorcida das realidades que esses fenómenos muitas vezes em si mesmo confinam.

No fundo, são situações que se refletem no conjunto dos comportamentos escolares, nas relações instituídas em contexto educativo, no papel dos diferentes atores. São situações que mais não fazem que destacar uma caraterística essencial da escola, associada que está aos seus contextos sociais, onde, como refere Innerarity (2006, p. 166), “(...) as sociedades atuais perderam aquela inocente homogeneidade de que se haviam revestido noutras épocas ignorando injustamente, por vezes, as diferenças que continham. A atual paisagem social e política apresenta uma topografia muito complicada (...). O mundo hoje carateriza-se pelo paradoxo de uma crescente globalização ser acompanhada por novas diferenciações, de haver mais relações entre um número maior de elementos (...)”.

Por conseguinte, as circunstâncias atuais colocaram a escola na primeira linha de um certo "contágio por osmose”, pois esta não ficou, nem poderia ficar, tendo em conta a sua função integradora, imune, e, talvez por isso, não ficou indiferente, pois perdeu "aquela inocente homogeneidade" para integrar no seu seio elementos de outras origens, povos, sujeitos, com diferentes línguas, religiões e culturas, o que a transformou numa espécie de "entreposto cultural” (Torres, 2008).

Assim, considerando a multiplicidade de comportamentos contidos pelos conceitos e contextos em causa, Amado (2001) distingue níveis de indisciplina, que aponta como desvio às regras de trabalho na aula, indisciplina perturbadora das relações entre pares e problemas da relação professor/aluno.

No primeiro nível, o autor procura caracterizar fundamentalmente os seus fatores e as suas funções, no segundo nível dá especial atenção aos maus tratos entre iguais e no terceiro nível realça os problemas na relação professor/aluno. No entanto, poder-se-á também adiantar que aspetos ligados às próprias caraterísticas pessoais dos alunos podem ser causa de mau comportamento e indisciplina, principalmente, os relacionados a contextos de nível psicológico. Assim, segundo Lopes (2009), por detrás de alunos indisciplinados, algumas vezes, escondem-se transtornos 
psicológicos e distúrbios da personalidade com vários níveis de patologias, como a hiperatividade e transtorno de oposição/desafio.

Convém lembrar aqui que hoje nas nossas escolas é frequente encontrar um número acentuado de alunos medicados com, Ritalina (metilfenidato): Medicamento para TDAH - Déficit de Atenção e Hiperatividade, um fármaco, estimulante (leve) do sistema nervoso central, com mecanismos de ação que, segundo a evidência científica, ainda não estão muito bem esclarecidos. De qualquer modo, parece-nos pacífico afirmar que, não só em Portugal mas também em vários outros países, as questões ligadas à indisciplina escolar são vistas como o problema principal das escolas, tendo-se verificado um certo acréscimo de comportamentos enunciados como indisciplinados, o que se torna muito preocupante para as comunidades educativas.

A alteração dos métodos e dos conceitos não refletem ainda valores de harmonia, em que a liberdade se alia à ordem. Partilhamos a opinião de que o aumento de uma certa consciencialização dos direitos dos alunos veio abalar os métodos tradicionais de disciplina em que muitos pais e alguns professores encontravam segurança sem que, entretanto, tenham adquirido novas competências educacionais e pedagógicas para lidarem com estas novas situações. Para Veiga (2002, p. 10), “o desenvolvimento da pessoa e da moralidade social requeria novos métodos para a resolução dos conflitos".

Será assim pertinente levantar a questão e perguntar se no nosso país ou nos países onde esta questão tem tido picos agudos de ocorrências anormais de indisciplina escolar, se se tem feito tudo o que é oportuno fazer para reforçar as competências relacionais quer nas famílias e com as famílias, quer na escola quer com a escola, uma vez que ao que se assiste é a uma precária evolução da educação para a relação no âmbito familiar e escolar.

É nesta linha que Veiga (2004) refere que a prevenção da indisciplina exige à família, em primeiro lugar, e, posteriormente, à escola como organização, onde os professores pela sua função específica detêm um papel primordial, uma conjugação de esforços muito elevada e expressiva. Esta ideia parece-nos basilar para que de forma abrangente e sustentada se logre dar corpo a uma escola mais harmoniosa, onde dê gosto aprender e dê gosto ensinar, trabalhar, em suma, dê gosto contribuir para a construção de cidadãos do, e para o futuro.

Tendo por base o enquadramento teórico anteriormente descrito, salientamos que o principal objetivo deste estudo foi explorar as relações 
existentes entre um conjunto de determinantes de contexto sociodemográfico, familiar e religioso e a indisciplina escolar percepcionada por uma amostra de alunos portugueses.

\section{MATERIAL E MÉTODOS}

Em qualquer investigação é essencial proceder ao enquadramento da metodologia, que pressupõe um processo racional e um conjunto de técnicas ou de meios que permitem realizar a investigação. Neste pressuposto, salientamos que a investigação levada a efeito insere-se num tipo de estudo não experimental, de natureza quantitativa, transversal, seguindo uma via descritivo-correlacional. Recorreu-se a uma amostra não probabilística e de conveniência, constituída por 772 jovens adolescentes que frequentavam a escola pública portuguesa no $3^{\circ}$ ciclo do ensino básico, no distrito da Guarda. Uma descrição mais detalhada da composição desta amostra, tendo em conta a sua distribuição por, idade, género, área de residência, ano de escolaridade e classe socioeconómica de pertença, está bem exposta no quadro 1 :

\section{Quadro 1}

Características gerais da amostra utilizada no estudo $(\mathrm{n}=772)$

\begin{tabular}{|c|c|c|}
\hline Idade $(\mathrm{M}=13,34, \mathrm{DP}=1,04)$ & $\mathrm{N}$ & $\%$ \\
\hline 12 & 183 & 23,7 \\
\hline 13 & 272 & 35,2 \\
\hline 14 & 229 & 29,7 \\
\hline 15 & 61 & 7,9 \\
\hline 16 & 24 & 3,1 \\
\hline 17 & 3 & 0,4 \\
\hline Género & $\mathrm{N}$ & $\%$ \\
\hline Mulheres & 402 & 52,1 \\
\hline Homens & 370 & 47,9 \\
\hline Área de Residência & $\mathrm{N}$ & $\%$ \\
\hline Rural & 395 & 51,2 \\
\hline Urbana & 377 & 48,8 \\
\hline Ano de escolaridade que frequentam os sujeitos & $\mathrm{N}$ & $\%$ \\
\hline $7^{\circ}$ & 322 & 41,7 \\
\hline $8^{\circ}$ & 231 & 29,9 \\
\hline $9^{\circ}$ & 219 & 28,4 \\
\hline Classe Socioeconómica & $\mathrm{N}$ & $\%$ \\
\hline Classe I - Classe Alta & 36 & 4,7 \\
\hline Classe II - Classe Média Alta & 253 & 32,8 \\
\hline Classe III - Classe Média & 374 & 48,4 \\
\hline Classe IV - Classe Média Baixa & 103 & 13,3 \\
\hline Classe V - Classe Baixa & 6 & 0,8 \\
\hline
\end{tabular}


O instrumento de colheita de dados, com incorporação de medidas de avaliação aferidas e validadas para a população portuguesa, era constituído por: uma ficha de caracterização sociodemográfica; uma ficha de caracterização familiar; uma ficha de caracterização de indicadores de âmbito religioso; a variável indisciplina escolar percepcionada pelos alunos portugueses foi avaliada pela EIEPA - Escala Indisciplina Escolar Percepcionada por Alunos de Videira e Albuquerque (2015). De salientar que solução fatorial final encontrada para esta Escala permitiu a seleção de 4 fatores, com raízes latentes "Eigenvalues”, superiores a 1,00 que no seu conjunto explicam $(55,749 \%)$ da variância com um resultado de Alpha de Cronbach apurado para o total da escala de $(0,960)_{2}$ o que é considerado muito bom. Os 4 factores são: fator $F_{1}$ - Desobediência transgressão; fator $F_{2}$ - Relacionamento interpessoal, o $F_{3}$ - Distração desinteresse; e $F_{4}$ Atitudes posturas.

Previamente à colheita de dados foi solicitado o parecer de uma comissão de ética, bem como expresso formalmente o consentimento informados dos estrudantes participantes no estudo. $O$ tratamento estatístico dos dados referentes foi efetuado informaticamente utilizando o programa Statistical Package for the Social Sciences (SPSS), versão 21.0 para Windows.

\section{APRESENTAÇÃO DOS RESULTADOS}

\subsection{Estudo das Variáveis SociodemográficaS}

\section{IDADE}

Para estudar a associação entre a idade e os resultados da escala Indisciplina Escolar Percecionada por Alunos, realizámos correlações de Pearson cujos resultados estão contextualizados no quadro 2:

\section{Quadro 2}

Correlações de Pearson - associação da variável idade com a Escala Indisciplina Escolar Percecionada por Alunos

\begin{tabular}{|lll|}
\hline Fatores da escala (EIEPA) & $\mathbf{r}$ & $\mathbf{p}$ \\
\hline F1 - Desobediência Transgressão &, 116 & $\mathbf{, 0 0 1}$ \\
F2 - Relacionamento Interpessoal &, 105 & $\mathbf{, 0 0 3}$ \\
F3 - Distração Desinteresse &, 058 &, 109 \\
F4 - Atitudes Posturas &, 054 &, 135 \\
\hline Nota Global da Escala &, 104 & $\mathbf{0 0 4}$ \\
\hline
\end{tabular}


Como se pode constatar, os dados revelam a existência de três associações positivas muito significativa nos fatores, F1 - Desobediência Transgressão, $(\mathrm{r}=, 116 ; \mathrm{p}=, 001), \mathrm{F} 2$ - Relacionamento Interpessoal, $(\mathrm{r}=, 105 ; \mathrm{p}=, 003)$ e Nota Global da Escala, $(\mathrm{r}=, 104 ; \mathrm{p}=, 004)$. Assim, poderemos considerar que apesar do peso das associações ser muito baixo, é lícito afirmar que à medida que a idade dos sujeitos aumenta estes pontuam mais, pelo que poderemos inferir que denotam uma mais baixa perceção dos comportamentos indisciplinados avaliados através da escala EIEPA. Por conseguinte, estes resultados levam-nos a aceitar de que o efeito da idade nos resultados obtidos na escala (EIEPA), nomeadamente, nos fatores, F1 - Desobediência Transgressão, F2 - Relacionamento Interpessoal e Nota Global da Escala adquirem significância estatística

\section{GÉNERO}

Os resultados obtidos pelos testes $t$ de Student inerentes à influência da variável género na Indisciplina Escolar Percecionada por Alunos estão apresentados no quadro 3. Os mesmos permitem constatar que os sujeitos do género feminino pontuam significativamente mais baixo que os sujeitos do género masculino nos resultados obtidos nos fatores/dimensões da escala (EIEPA), nomeadamente no fator F1 - Desobediência Transgressão, F2 - Relacionamento Interpessoal, F3 - Distração Desinteresse e Nota Global da Escala. Face a esta evidência, poderemos presumir que os sujeitos do género feminino têm uma perceção dos comportamentos indisciplinados mais acentuada de que os sujeitos do género masculino.

\section{Quadro 3}

Testes t de Student - Variável Género, Escala Indisciplina Escolar Percecionada por Alunos

\begin{tabular}{|lcccccc|}
\hline \multicolumn{7}{|c|}{ Género } \\
\hline & $\begin{array}{l}\text { Mulheres } \\
(\mathrm{n}=402)\end{array}$ & $\begin{array}{c}\text { Homens } \\
(\mathrm{n}=370)\end{array}$ & test $t$ & $\mathrm{p}$ \\
\hline F & $\mathrm{M}$ & $\mathrm{DP}$ & $\mathrm{M}$ & $\mathrm{DP}$ & & \\
F $_{1}$ - Desobediência Transgressão & 31,05 & 8,09 & 32,53 & 9,61 & $-2,303$ & $\mathbf{, 0 2 2}$ \\
F $_{2}$ - Relacionamento Interpessoal & 12,21 & 3,53 & 14,47 & 5,54 & $-6,665$ & $\mathbf{, 0 0 0}$ \\
F $_{3}$ - Distração Desinteresse & 16,37 & 4,28 & 17,55 & 5,53 & $-3,287$ & $\mathbf{, 0 0 1}$ \\
F4 - Atitudes Posturas & 12,45 & 2,93 & 12,51 & 3,20 &,- 238 &, 812 \\
\hline Nota Global da Escala & 72,08 & 16,46 & 77,05 & 21,12 & $-3,620$ & $\mathbf{, 0 0 0}$ \\
\hline
\end{tabular}




\section{LOCAL DE RESIDÊNCIA}

Em relação à influência da variável local de residência, os testes $t$ de Student (cf. Quadro 4), permitem constatar que são os sujeitos residentes no meio rural que globalmente apresentam scores mais elevados, quando comparados com os dos que residem no meio urbano. No entanto, as diferenças obtidas entre os dois grupos só se revelaram estatisticamente significativas no fator F2 - Relacionamento Interpessoal.

Assim, poderemos presumir que são os sujeitos que residem no meio urbano a evidenciar uma perceção dos comportamentos indisciplinados mais acentuada comparativamente aos sujeitos que residem no meio rural, no que se refere ao fator F2 - Relacionamento Interpessoal.

\section{Quadro 4}

Testes t de Student - Variável Local de Residência, Escala Indisciplina Escolar Percecionada por Alunos

\begin{tabular}{|c|c|c|c|c|c|c|}
\hline \multicolumn{7}{|c|}{ Local de Residência } \\
\hline & \multicolumn{2}{|c|}{$\begin{array}{l}\text { Meio Rural } \\
(n=395)\end{array}$} & \multicolumn{2}{|c|}{$\begin{array}{l}\text { Meio Urbano } \\
(\mathrm{n}=377)\end{array}$} & \multirow[t]{2}{*}{ test $t$} & \multirow[t]{2}{*}{$\mathrm{p}$} \\
\hline & M & DP & M & DP & & \\
\hline F1 - Desobediência Transgressão & 31.77 & 8,95 & 31,75 & 8,82 & 034 & 973 \\
\hline$F_{2}$ - Relacionamento Interpessoal & 13.64 & 4,97 & 12,93 & 4,47 & 2,096 & ,036 \\
\hline$F_{3}$ - Distração Desinteresse & 17,07 & 4,98 & 16,79 & 4,93 & 808 & 419 \\
\hline $\mathrm{F}_{4}-$ Atitudes Posturas & 12,49 & 3,07 & 12,47 & 3,07 & 075 & 940 \\
\hline Nota Global da Escala & 74,97 & 19,30 & 73,93 & 18,67 & ,761 & ,447 \\
\hline
\end{tabular}

\section{ESTUDO DE VARIÁVEIS DE CONTEXTO RELIGIOSO}

$\mathrm{O}$ estudo da dimensão religiosa centrou-se em alguns indicadores, nomeadamente no que diz respeito ao facto dos sujeitos acreditarem ou não em alguma religião. Das respostas obtidas, embora se possa globalmente verificar que os sujeitos que responderam "sim" pontuarem mais baixo do que os que dizem que "não", a verdade é que essas diferenças não se revelaram estatisticamente significativas.

Questionámos ainda os sujeitos (que tinham respondido que acreditavam numa religião) qual era a religião em que acreditavam. Tendo em conta as respostas que obtivemos, optámos por constituir dois grupos. Um, que era a maioria, respondeu que acreditava na Religião Católica e outro respondeu que acreditava em outra religião (grupo muito reduzido e que engloba respondentes que dizem acreditar nas religiões: Muçulmana, Hindu, Ortodoxa e outras). Os resultados obtidos com recurso à aplicação dos testes t de Student permitem constatar que os respondentes que dizem praticar a Religião Católica pontuam mais do que os que dizem praticar 
outras Religiões, embora também não se tenham obtido resultados estatisticamente significativos.

No entanto, outros resultados relativos ao contexto religioso proferidos pelos sujeitos da nossa amostra e que se revelaram muito interessantes dizem respeito ao grau de Crença na Religião e ao grau de Praticante, que de seguida serão apresentados (para esta mensuração foi utilizada uma escala de resposta tipo likert de 1 - muito pouco a 7pontos - muitíssimo).

\section{GRAU DE CRENÇA NA RELIGIÃO QUE PRATICA O SUJEITO}

As Anova(s) realizadas (cf. Quadro 5) mostram o efeito da variável Grau de Crença na Religião que pratica o sujeito, registando-se a existência de um efeito estatisticamente significativo em todos os fatores incluindo a nota global da escala (EIEPA).

\section{Quadro 5}

Anova $_{(s)}$ - Grau de Crença na Religião que pratica o sujeito sobre os fatores e a Nota Global da Escala (EIEPA)

\begin{tabular}{|lllll|}
\hline \multicolumn{5}{|c}{ Grau de Crença na Religião que pratica o sujeito } \\
G L Efeito $=2$ & $\begin{array}{l}\text { Média Quadr. } \\
\text { Efeito }\end{array}$ & $\begin{array}{l}\text { Média Quadr. } \\
\text { Erro }\end{array}$ & F & p \\
\hline F1 - Desobediência Transgressão & 1389,272 & 694,636 & 9,104 & $\mathbf{, 0 0 0}$ \\
F2 - Relacionamento Interpessoal & 296,628 & 148,314 & 6,827 & $\mathbf{, 0 0 1}$ \\
F3 - Distração Desinteresse & 204,943 & 102,472 & 4,374 & $\mathbf{, 0 1 3}$ \\
F4 - Atitudes Posturas & 109,148 & 54,574 & 6,169 & $\mathbf{, 0 0 2}$ \\
Nota Global da Escala & 6161,247 & 3080,623 & 8,948 & $\mathbf{, 0 0 0}$ \\
\hline
\end{tabular}

Após a realização de testes post-hoc de Tukey, foram localizadas as diferenças entre grupos encontrando-se os resultados esquematizados nos quadros que de seguida se apresentam. 


\section{Quadro 6}

Testes de Tukey: Grau de Crença na Religião que praticam os sujeitos sobre os fatores e a Nota Global da Escala (EIEPA)

\begin{tabular}{|c|c|c|c|c|}
\hline \multicolumn{5}{|l|}{$\begin{array}{l}1 \text { - Crença Baixa } \\
2 \text { - Crença Média } \\
3 \text { - Creça Alta }\end{array}$} \\
\hline \multirow[t]{3}{*}{ F1 - Desobediência Transgressão } & $1(34,82)$ & $2(31,90)$ & 2,925 & ,038 \\
\hline & & $3(29,47)$ & 5,355 & ,000 \\
\hline & 2 & 3 & 2,430 & ,009 \\
\hline \multirow[t]{2}{*}{ F2 - Relacionamento Interpessoal } & $1(14,56)$ & $2(13,43)$ & $\begin{array}{l}1,136 \\
2,379\end{array}$ & ,174 \\
\hline & 2 & 3 & 1,242 & 013 \\
\hline \multirow[t]{2}{*}{ F3 - Distração Desinteresse } & $\mathbf{1}(17,95)$ & $\begin{array}{l}2(16,98) \\
3(15,96)\end{array}$ & $\begin{array}{l}, 971 \\
1,990\end{array}$ & $\begin{array}{l}305 \\
, 017\end{array}$ \\
\hline & 2 & 3 & 1,019 & 066 \\
\hline \multirow[t]{2}{*}{ F4 - Atitudes Posturas } & $1(12,98)$ & $\begin{array}{l}2(12,73) \\
3(11,81)\end{array}$ & $\begin{array}{l}254 \\
1,170\end{array}$ & $\begin{array}{l}806 \\
, \mathbf{0 2 4}\end{array}$ \\
\hline & 2 & 3 & ,916 &, 003 \\
\hline \multirow[t]{2}{*}{ Nota Global da Escala } & $1(80,32)$ & $\begin{array}{l}2(75,04) \\
3(69,43)\end{array}$ & $\begin{array}{l}5,286 \\
10,893\end{array}$ & $\begin{array}{l}092 \\
, 000\end{array}$ \\
\hline & 2 & 3 & 5,607 & ,004 \\
\hline
\end{tabular}

No que respeita à localização das diferenças estatisticamente significativas entre médias obtidas pelos grupos que se formaram e a escala (EIEPA), poderemos constatar que elas existem em todos os fatores. Em suma, poder-se-á constatar que em todos os factores da escala (EIEPA) incluindo a nota global ocorrem diferenças entre as médias obtidas por grupos de adolescentes com graus de crença diferenciados na sua Religião, podendo-se afirmar que, genericamente, são os sujeitos cujo grau de crença é mais elevado na sua Religião a evidenciar scores mais baixo na escala (EIEPA), o que significa uma perceção mais acentuada dos comportamentos indisciplinados na escola.

\section{GRAU DE PRÁTICA RELIGIOSA COM A ESCALA (EIEPA)}

As Anovas realizadas, no quadro seguinte, apresentam o efeito da variável Grau de Práticas Religiosas que o sujeito pratica inferida pelo próprio, registando-se a existência de um efeito estatisticamente muito significativo em todos os fatores incluindo a nota global da Escala (EIEPA): 


\section{Quadro 7}

Anova $_{(\mathrm{s})}$ Grau de Práticas Religiosas sobre os fatores e a Nota Global da Escala (EIEPA)

\begin{tabular}{|lllll|}
\hline \multicolumn{5}{c}{ Grau de Práticas Religiosas } \\
G L Efeito $=2$ & $\begin{array}{l}\text { Média Quadr. } \\
\text { Efeito }\end{array}$ & Média Quadr. & F & \multirow{2}{*}{ Erro } \\
\hline F L Erro = 626 & 2529,013 & 1264,506 & 16,977 & $\mathbf{, 0 0 0}$ \\
F - Desobediência Transgressão & 284,299 & 142,149 & 6,537 & $\mathbf{, 0 0 2}$ \\
F - Relacionamento Interpessoal & 324,897 & 162,449 & 6,992 & $\mathbf{, 0 0 1}$ \\
F - Distração Desinteresse & 237,353 & 118,677 & 13,734 & $\mathbf{, 0 0 0}$ \\
F4 - Atitudes Posturas & 9882,962 & 4941,481 & 14,605 & $\mathbf{, 0 0 0}$ \\
Nota Global da Escala & & & & \\
\hline
\end{tabular}

Após a realização de testes post-hoc de Tukey, foram localizadas as diferenças das médias entre grupos, encontrando-se os resultados esquematizados no quadro 8:

\section{Quadro 8}

Testes de Tukey: Grau de Pratica Religiosa inferida pelo sujeito sobre os fatores e a Nota Global da Escala (EIEPA)

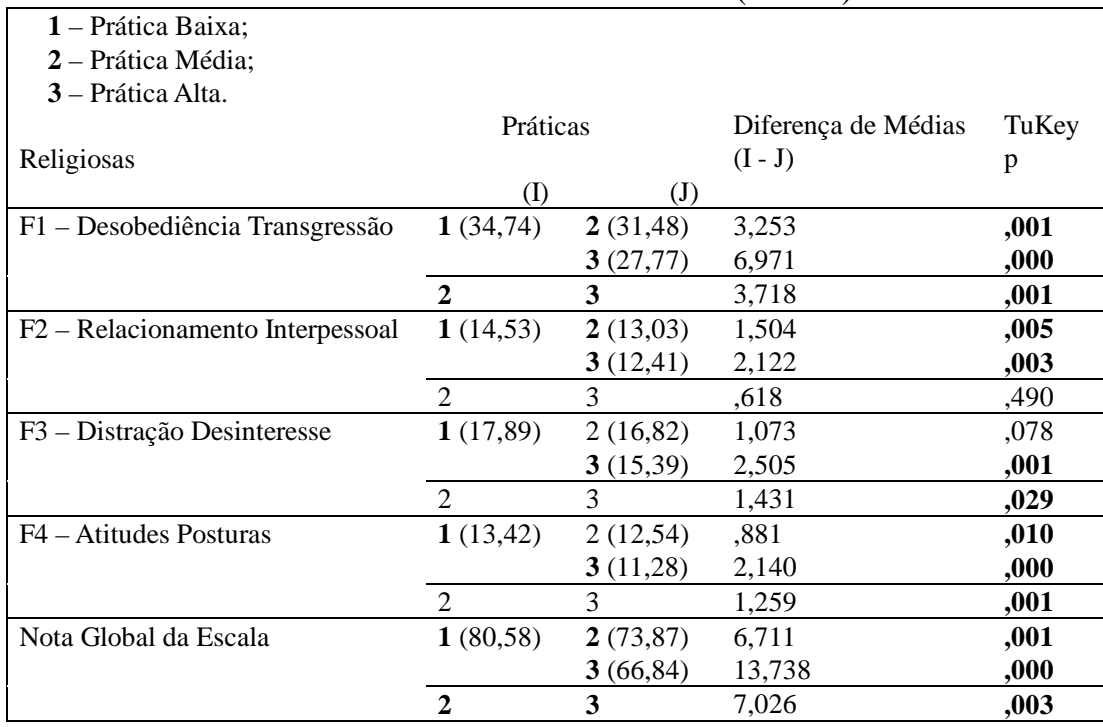

No que respeita à localização das diferenças estatisticamente significativas, entre as médias obtidas pelos grupos que se formaram e a escala (EIEPA), poderemos constatar que elas existem em todos os fatores. 
Em suma, poder-se-á constatar que em todos os fatores da escala (EIEPA) incluindo a Nota Global, ocorrem diferenças entre as médias obtidas por grupos de adolescentes com graus diferenciados de prática da religião em que acreditam, apresentando resultados estatisticamente significativos. Podemos, assim, afirmar que são os sujeitos mais empenhados na sua prática religiosa a apresentar scores mais baixo na escala (EIEPA), sendo, pois, mais alta a sua perceção dos comportamentos indisciplinados na escola.

\section{ESTUDO DAS VARIÁVEIS DE CONTEXTO FAMILIAR}

De seguida serão apresentados alguns resultados subjacentes ao estudo da influência que algumas variáveis de caráter sociofamiliar têm sobre os comportamentos indisciplinados em ambiente escolar percepcionados pelos alunos.

EXISTÊNCIA DE CONVERSAS COM O ENCARREGADO DE EDUCAÇÃO SOBRE A FORMA COMO O ESTUDANTE DE COMPORTA NA ESCOLA

As Anova(s) realizadas e que se apresentam no quadro que se segue exibem o efeito da variável mensurada pela questão: Conversas com o teu encarregado de educação sobre a forma como te comportas na escola? Como poderemos verificar, os mesmos são estatisticamente significativos (cf. Quadro 9).

\section{Quadro 9}

Anova $_{(\mathrm{s})}$ - Conversas com o teu encarregado de educação sobre a forma como te comportas na escola sobre os fatores e a Nota Global da Escala (EIEPA)

\begin{tabular}{|lllll|}
\hline \multicolumn{5}{|c}{ Conversas com o teu encarregado de educação sobre a forma como te comportas na escola } \\
G L Efeito $=3$ & $\begin{array}{l}\text { Média } \\
\text { Quadr. } \\
\text { E L Erro }=768\end{array}$ & $\begin{array}{l}\text { Média } \\
\text { Quadr. } \\
\text { Erro }\end{array}$ & F & p \\
\hline F1 - Desobediência Transgressão & 1700,863 & 566,954 & 7,364 & $\mathbf{, 0 0 0}$ \\
F - Relacionamento Interpessoal & 256,348 & 85,449 & 3,837 & $\mathbf{, 0 1 0}$ \\
F3 - Distração Desinteresse & 541,314 & 180,438 & 7,537 & $\mathbf{, 0 0 0}$ \\
F4 - Atitudes Posturas & 213,236 & 71,079 & 7,757 & $\mathbf{, 0 0 0}$ \\
Nota Global da Escala & 8897,355 & 2965,785 & 8,458 & $\mathbf{, 0 0 0}$ \\
\hline
\end{tabular}

Após a realização de testes post-hoc de Tukey, foram localizadas as diferenças das médias entre grupos, encontrando-se os resultados agrupados no quadro que se segue: 


\section{Quadro 10}

Testes de Tukey - Conversas com o teu encarregado de educação sobre a forma como te comportas na escola, sobre os fatores e a Nota Global da Escala

\section{(EIEPA)}

\begin{tabular}{|c|c|c|c|c|}
\hline \multicolumn{3}{|c|}{$\begin{array}{ll}\text { - Todos os dias; } & 3 \text { - } 1 \text { vez por mês; } \\
2 \text { - Semanalmente; } & 4 \text { - Nunca. } \\
\text { Conversas com o teu encarregado de educação sobre a forma } \\
\text { como te comportas na escola }\end{array}$} & \multirow{2}{*}{$\begin{array}{l}\text { Diferença de } \\
\text { Médias } \\
\text { (I - J) }\end{array}$} & \multirow{2}{*}{$\begin{array}{l}\text { TuKe } \\
\mathrm{y} \\
\mathrm{p}\end{array}$} \\
\hline & (I) & $(\mathrm{J})$ & & \\
\hline \multirow[t]{6}{*}{ F1 - Desobediência Transgressão } & $\mathbf{1}(30,63)$ & $2(32,02)$ & $-1,389$ & ,223 \\
\hline & & $3(34,54)$ & $-3,916$ & ,000 \\
\hline & & $4(35,00)$ & $-4,372$ &, 025 \\
\hline & 2 & 3 & $-2,526$ & ,073 \\
\hline & & 4 & $-2,982$ & 241 \\
\hline & 3 & 4 &,- 456 & ,993 \\
\hline \multirow[t]{6}{*}{ F2 - Relacionamento Interpessoal } & $1(12,90)$ & $2(13,30)$ &,- 394 & ,744 \\
\hline & & $3(14,24)$ & $-1,339$ & ,050 \\
\hline & & $4(15,00)$ & $-2,096$ & , 057 \\
\hline & 2 & 3 &,- 944 & ,332 \\
\hline & & 4 & $-1,702$ & 194 \\
\hline & 3 & 4 &,- 757 & 845 \\
\hline \multirow[t]{6}{*}{ F3 - Distração Desinteresse } & $1(16,36)$ & $2(16,95)$ &,- 587 & 468 \\
\hline & & $3(18,26)$ & $-1,898$ & ,003 \\
\hline & & $4(19,49)$ & $-3,121$ &, 002 \\
\hline & 2 & 3 & $-1,310$ & 109 \\
\hline & & 4 & $-2,534$ & ,023 \\
\hline & 3 & 4 & $-1,224$ & ,577 \\
\hline \multirow[t]{6}{*}{ F4 - Atitudes Posturas } & $1(12,13)$ & $2(12,44)$ &,- 315 & ,591 \\
\hline & & $3(13,58)$ & $-1,454$ & ,000 \\
\hline & & $4(13,51)$ & $-1,386$ & ,047 \\
\hline & 2 & 3 & $-1,140$ & ,009 \\
\hline & & 4 & $-1,071$ & ,208 \\
\hline & 3 & 4 & ,068 & (999 \\
\hline \multirow[t]{6}{*}{ Nota Global da Escala } & $1(72,02)$ & $2(74,71)$ & $-2,686$ & ,307 \\
\hline & & $3(80,63)$ & $-8,606$ & ,000 \\
\hline & & $4(83,00)$ & $-10,975$ & ,005 \\
\hline & 2 & 3 & $-5,921$ & ,039 \\
\hline & & 4 & $-8,289$ & ,071 \\
\hline & 3 & 4 & $-2,369$ & 917 \\
\hline
\end{tabular}

Para responderem a esta variável os sujeitos tinham quatro opções de resposta: 1 - todos os dias; 2 - Semanalmente; 3 - 1 vez por mês; 4 - Nunca.

Assim, tendo como referência os resultados alcançados, poderemos concluir que os valores obtidos vão no sentido de podermos dizer que os adolescentes que têm um diálogo com o seu encarregado de educação mais frequente sobre o seu comportamento na escola pontuam globalmente menos do que os que o fazem com menos frequência ou mesmo nunca o 
fazem, o que sugere que os que o fazem com mais frequência denotam uma perceção dos comportamentos indisciplinados mais acentuada.

Fazendo uma leitura mais pormenorizada dos dados obtidos, poder-se-á verificar que encontrámos resultados estatisticamente significativos que confirmam que os Alunos que conversam com mais frequência com o seu encarregado de educação sobre o seu comportamento na escola, nos fatores F1 - Desobediência Transgressão, F3 - Distração Desinteresse; F4 Atitudes Posturas, e Nota Global da Escala, denotam de forma significativa uma perceção dos atos indisciplinados melhor do que aqueles que nunca o fazem ou o fazem com menos frequência.

Em suma, tais resultados levam-nos a aceitar de que existem diferenças estatisticamente significativas entre as médias obtidas nos fatores, F1 Desobediência Transgressão, F3 - Distração Desinteresse; F4 - Atitudes Posturas, e Nota Global da Escala (EIEPA) por grupos de adolescentes que têm frequentemente diálogos com o seu encarregado de educação sobre a forma como se comportam na escola.

\section{CONCLUSÃO}

Integrar e articular a informação recolhida nesta investigação, ainda que de forma sintetizada, é por certo essencial, realçando de forma mais enfática os resultados que estão subjacentes à predição da perceção dos comportamentos indisciplinados dos Alunos que frequentam o $3^{\circ}$ ciclo do Ensino Básico no sistema educativo público português, em particular, os que o frequentam no Distrito da Guarda. Pelos resultados alcançados, poderemos afirmar com alguma segurança que o modelo que serviu de suporte a esta investigação, isto é, o modelo conceptual que foi construído por nós e fundamentou toda esta Investigação, revela que a perceção dos comportamentos indisciplinados pelos Alunos que frequentam o $3^{\circ}$ ciclo do Ensino Básico no sistema educativo público português é influenciada por fatores dos contextos sociofamiliar, religioso e familiar.

No que respeita à variável género, poderemos verificar que, de forma generalizada, os sujeitos do género feminino pontuam menos do que os sujeitos do género masculino, o que nos leva a considerar que os sujeitos do género feminino denotam uma perceção dos comportamentos indisciplinados na escola com maior ponderação do que os sujeitos do género masculino.

No que respeita à variável, zona de residência, os resultados que obtivemos vão no sentido de podermos verificar que de forma generalizada 
os sujeitos que residem em zonas rurais pontuam mais na escala (EIEPA) do que os que residem em zonas urbanas, pontuando de forma estatisticamente significativa no fator F2 - Relacionamento Interpessoal, o que nos leva a considerar que os sujeitos que residem em zonas urbanas têm uma perceção dos comportamentos indisciplinados na escola mais acentuada do que os que residem em zonas rurais.

Relativamente às variáveis de contexto religioso, domínio nunca antes estudado no território nacional, foi possível verificar que globalmente os adolescentes que professam uma religião e que dizem acreditar na sua religião de uma forma mais determinada pontuam menos na escala (EIEPA) do que aqueles que dizem ter uma crença mais contida, sendo de salientar que estes dados têm significância estatística manifesta, pelo que poderemos avançar com a ideia que os Alunos adolescentes que acreditam de forma mais firme na sua crença religiosa têm uma perceção dos comportamentos indisciplinados na escola mais acentuada do que aqueles que têm uma crença mais débil.

No que respeita à intensidade da prática religiosa que os Alunos adolescentes dizem ter, poderemos verificar que os que têm uma prática religiosa mais intensa de forma global e estatisticamente significativa denotam uma perceção dos comportamentos indisciplinados mais acentuada do que aqueles que responderam ter uma prática religiosa menos comprometida.

Relativamente às variáveis independentes do contexto sociofamiliar quando questionámos os Alunos se; conversavam com o seu encarregado de educação sobre a forma como se comportavam na escola, constatámos que de forma clara, global e estatisticamente significativa, os Alunos que referiram que o faziam com mais frequência pontuavam menos do que aqueles que referiram que nunca o faziam ou o faziam poucas vezes, o que nos leva a afirmar que os sujeitos que têm um diálogo mais frequente com os seus encarregados de educação sobre a forma como se comportam na escola denotam uma maior perceção dos comportamentos indisciplinados do que os que não têm um diálogo tão acentuado.

Em suma, as inferências resultantes deste estudo convidam-nos à reflexão sobre a importância da criação e monitorização de programas de ação no domínio da prevenção ou de contingência para uma efetiva redução dos comportamentos indisciplinados perpetrados por alunos no seio da Escola. Para tal não deve ser descorado o ambiente social, familiar e até religioso que circunstancia o dia a dia do aluno. Por outro lado não 
nos devemos alhear da responsabilidade que o seio familiar deverá ter em toda esta intervenção, complementado pela ESCOLA, percepcionada como o espaço de eleição para intervir de uma forma diferenciada e interdisciplinar.

Neste contexto, poemos afirmar que a escola como unidade social organizada que é, procura atingir metas, patamares de realização pessoal e de grupo, que manifestamente estão definidos no seu contrato social de prestação de um serviço público de educação de qualidade para todos. Para Etzioni (1993, citado por Teixeira, 1995, p. 36) "os objetivos constituem também, uma fonte de legitimidade que justifica as atividades de uma organização e na verdade, até a sua existência".

Com efeito, as organizações normalmente detêm no seu seio órgãos próprios para definir os objetivos dessa organização, e a sua eficiência pode ser avaliada em função da medida em que esses objetivos são atingidos ou não. Todos bem sabemos que as escolas não são todas iguais. Existem particularidades várias que lhes conferem uma identidade própria fruto de um conjunto de contextos singulares. Poder-se-á assim dizer que as escolas e a perceção que delas temos são muitas vezes consequência de um certo clima que nelas se experienciam.

Poderemos pois afimar que o clima de escola reflete a imagem interna que as pessoas têm da organização a nível do contexto de trabalho, "da atmosfera psicológica, humana e social” como alude Fachada (2001, p. 251), ou seja, reflete "as perceções que os atores têm da organização" como bem diz Teixeira (1995, p. 165) e assim vai influenciando o comportamento e as relações entre os diversos intervenientes do processo educativo.

Neste sentido, Alves (1992, p. 43) evidencia o caráter plurívoco e intuitivo do conceito, afirmando que estamos perante "a perceção imediata por parte dos atores, das singularidades e da especificidade da organização". Assim, no decurso deste estudo vários foram os estudos que tivemos oportunidade de rever e que se referem a este contexto, o Clima de Escola, com a particularidade de todos eles realçarem a importância deste tema, bem como, das suas particularidades, apontando mesmo evidências da sua influência nos comportamentos dos alunos (Alves, 1992; Brunet, 1992; Freitas, 2002; Paiva, 2009; Teixeira,1995; Vale \& Costa, 1994; Veiga, 1995). 


\section{REFERÊNCIAS}

Albuquerque, C. M. (2004). Comportamientos de salud y de riesgo en la adolescencia. Tese de Doutoramento não Publicada. Badajoz: Universidade da Extremadura, Departamento de Psicologia e Educação.

Alonso, B. (2007). La disciplina Escolar en los distintos modelos pedagógicos. Revista de Ciências de la Educación, 131, 289-315.

Alves, J. (1992). Organização, Gestão e Projecto Educativo das Escolas. Correio Pedagógico, 5, 43-47.

Amado, J. (2001). Interação pedagógica e indisciplina na aula. Porto: Edições ASA.

Amado, J., \& Freire, I. (2005). A Gestão da sala de aula. Psicologia da educação, temas de desenvolvimento, aprendizagem e ensino, 311331

Amado, J., \& Freire, I. P. (2009). A(s) indisciplina(s) na escola: Compreender para prevenir. Coimbra: Almedina.

Brunet, L. (1992). Clima de trabalho e Eficácia da Escola. In, António Nóvoa (ed.). As Organizações Escolares em Análise. Lisboa: Publicações Dom Quixote, 121-139.

Chiavenato, I. (1993). Introdução à Teoria Geral da Administração. São Paulo: Makrou Books.

Estrela, M. (2004). Relação Pedagógica, disciplina e indisciplina na aula. (4. ed.). Porto: Porto Editora.

Fachada, M. O. (2001). Psicologia das relações interpessoais. ( $2^{\circ}$ vol.). Amadora: Rumo.

Freire, I. (2006). Percursos disciplinares e contextos escolares - Dois estudos de caso. Tese de Doutoramento não publicada. Lisboa: Faculdade de Psicologia e de Ciências da Educação da Universidade de Lisboa.

Freitas, M. E. D. (2002). Cultura organizacional grandes temas em debate. Revista de Administração de Empresas, 31(3), 73-82.

Innerarity, D. (2006). O novo espaço público. Lisboa: Teorema.

Lopes, J. (2009). Comportamento, aprendizagem e ensinagem. Na ordem e desordem na sala de aula. Braga: Psiquilíbrios Edições.

Maroco, J. (2011). Análise estatística com o SPSS Statistics. Lisboa: Report Number. 
Paiva, M. O. A. (2009). A dinâmica do autoconceito na disrupção escolar: Um estudo com alunos do 3. ${ }^{\circ}$ ciclo do ensino básico, trabalho de Pósdoutoramento não publicado. Porto: Universidade Fernando Pessoa.

Pestana, M.H., \& Gageiro, J.N. (2008). Análise de dados para ciências sociais: A complementaridade do SPSS. (5 ${ }^{\mathrm{a}}$ ed). Lisboa: Edições Sílabo.

Santos, F. (2013). Indisciplina escolar uma questão problemática!?. Lisboa: Novas Edições Académicas.

Teixeira, M. (1995). O Professor e a escola - Perspectivas organizacionais. Lisboa: Editora McGraw-Hill.

Torres, L. L. (2008). A escola como entreposto cultural: o cultural e o simbólico no desenvolvimento democrático da escola. Revista Portuguesa de Educação, 21(1), 59-81.

Vale, D., \& Costa, E. (1994). A violência nos jovens contextualizada nas escolas. Inovação, 7(3), 255-288.

Veiga, F. (1995). Transgressão e Autoconceito dos Jovens na Escola Investigação Diferencial. Lisboa: Fim de Século Edições.

Veiga, F. (2000). Violência dos Jovens nas Escolas em Função da Família. In A. Fontaine (Org.). Família-Escola e Desenvolvimento da Criança/Partenariado Familia-Escuela y Desarrolho de los Niños (pp. 121-142). Porto: Edições Asa.

Veiga, F. (2002). Indisciplina e violência na escola: Efeitos da autoridade psicodinâmica. In A Estrela \& J. Ferreira (Eds.), Violence et Indiscipline à l’Ecole/Violência e Indisciplina na escola. Lisboa.

Veiga, F. (2004). Indisciplina e violência na escola: Abordagens psicoeducacionais. Lisboa: Universidade Aberta. 